\title{
Advances in Catalysis for Organic Coatings
}

\author{
Werner J. Blank*
}

\begin{abstract}
The industrial coating market is undergoing substantial changes. These changes are driven predominately by environmental regulations. The reduction in organic solvent content and the elimination of certain heavy metals and toxic compounds in industrial coatings are major priorities.

The development of powder, waterborne, high solids or solvent-free coatings also requires catalyst systems with different reaction profiles.
\end{abstract}

Keywords: Amino resins · Catalyst · Environment · Epoxy · Polyurethane

\section{Introduction}

The industrial coating market is undergoing a considerable change, from coatings containing a large amount of organic solvents (high volatile organic content or high VOC) to either solvent-free, high solids coatings, waterborne or powder coatings. Besides the concern about VOC, other major forces have been the development of low energy-curing, coating systems and coatings which are less toxic during the application process and have less impact on the environment. To achieve the desired resistance properties, these industrial coatings require crosslinking.

Many of today's industrial coatings are, therefore, reactive systems consisting of

${ }^{*}$ Correspondence: W.J. Blank

King Industries, Inc.

Coatings Research Department

Science Road

Norwalk, CT 06897, USA

Tel.: +1 2038665551

Fax: +1 2038555605

E-Mail: wblank@kingindustries.com

www. kingindustries.com

www.wernerblank.com functional polymers and a crosslinking agent. These coating systems can be one package stable coatings or plural component systems (Table 1). For the reaction of a functional polymer with a crosslinking agent to proceed at an acceptable temperature or within a short time period, usually a catalyst is required. The criteria for the selection of a catalyst vary depending on the crosslinking chemistry, the application method, coating end-use and/or environmental or health concerns. Some catalysts, which give acceptable properties in low solids coatings, do not meet the requirements for the newer coatings. In high VOC coatings it is possible to achieve film properties little or no crosslinking. Therefore, potlife and cure response are easy to adjust. In high solids coatings using low MW oligomers, film formation is not possible without a substantial amount of crosslinking.

Fig. 1 illustrates this problem [1] in a high solids polyester/isocyanate crosslinker formulation. Potlife of the formulation (doubling of the viscosity) is rather short and tack free time is very long.
In this formulation, the maximum potlife is reached at approximately $7 \%$ conversion of the isocyanate and tack free time requires approximately $60 \%$ conversion of the isocyanate.

\section{Polyurethanes}

This versatile chemistry is used in elastomers, foams, sealants, adhesives and in coatings. Polyurethanes are prepared by the reaction of a polyisocyanate with a polyol. Either thermoplastic or thermoset polyurethanes are commercially available. The market for the lower cost aromatic isocyanates, which go into applications like elastomers and foams, is substantially larger than the aliphatic isocyanate market. Because of their improved light stability aliphatic isocyanates are used extensively in coatings. Aromatic and aliphatic isocyanates respond differently to catalysts. The performance requirement for a catalyst is different in coatings and in the preparation of polyurethane polymers.

Table 1. New technologies

$\begin{array}{llll}\text { High Solids } & \text { Solvent-free } & \text { Waterborne } & \text { Powder } \\ \begin{array}{llll}\text { One package } \\ \text { heat cured }\end{array} & \begin{array}{l}\text { One package } \\ \text { heat cured }\end{array} & \begin{array}{l}\text { One package } \\ \text { heat cured }\end{array} & \text { Heat cured } \\ \text { Two component } & \text { Two component } & \text { Two component } & \\ \text { UV curing } & \text { UV curing } & \text { UV curing } & \text { UV curing }\end{array}$




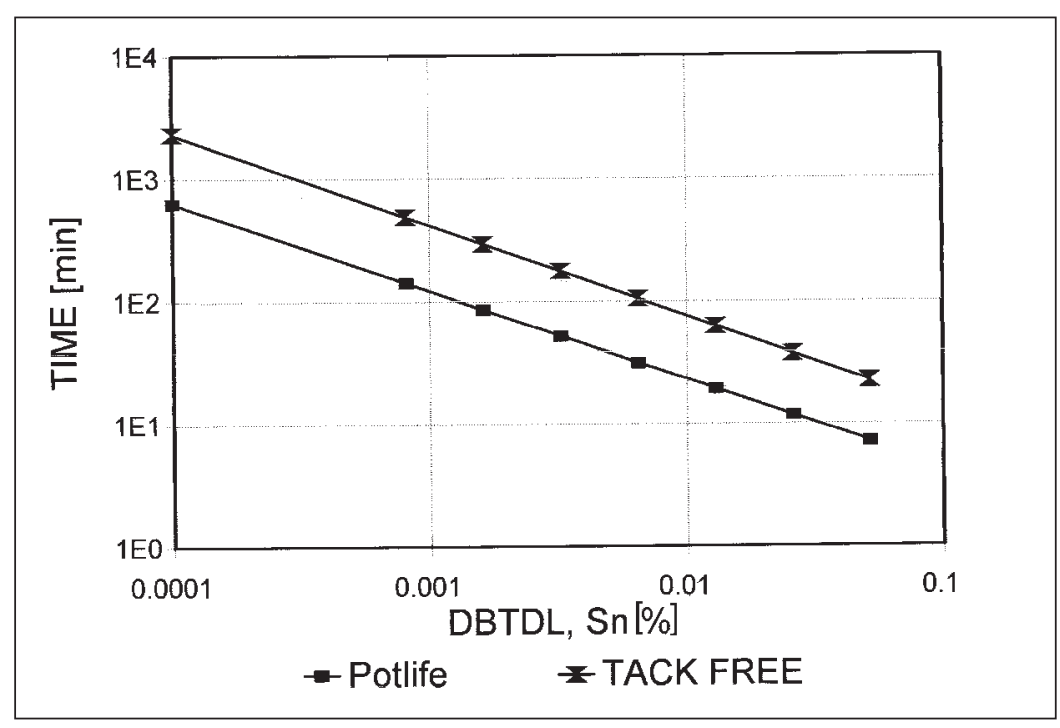

\section{Aromatic isocyanates}

For the catalysis of aromatic isocyanates, such as toluene diisocyanate (TDI) and methylene diphenylene diisocyanate (MDI), both amines and organotin compounds are used. Isocyanate catalysts can be classified depending on the reactions they catalyze and according to the applications in which they are used. For polyurethane foam catalysts we have to differentiate between trimerization catalysts, blowing catalysts and gelation catalysts. The catalysts used in the trimerization reaction are usually the carboxylate salts of strong bases, such as potassium [2] octoate or quaternary ammonium carboxylates [3]. The blowing catalysts catalyze the reaction of isocyanate with water, leading to the formation of carbon dioxide and a primary amine. The amine in turn will react with more isocyanate, thus leading to urea formation. The carbon dioxide formed acts as blowing agent for the foam, thus eliminating or reducing the need for fluorocarbon blowing agents. Excellent blowing catalysts are tertiary polyamines. The catalytic activity of these amines increases with the increase of multiple amine centers [4]. Typical catalysts are tetramethylethylenediamine, pentamethyldiethylenetriamine, 1,4-dimethylpiperazine and 1,2-dimethylimidazole, to name only a few. Most of the amine catalysts combine their catalytic activity with other properties, such as gelation. In automotive foam applications, however these tertiary amine catalysts present a problem because of volatility, which can lead to odor problems, staining and to fogging of the windows. For applications of foams in automotive seating, catalysts which have reactive groups, such as hydroxyl or
Fig. 1. High solids polyester polyol and 1,6-hexamethylenediisocyanate trimer. Potlife and tack free time. amine groups have found utility [5]. Some of the catalysts used in the automotive area are 1,1'-\{[3-(dimethylamino)propyl]imino\}bis(2-propanol), 1,3-bis(dimethylamino)-2-propanol and 2-[2-(dimethylamino) ethoxy]ethanol. To achieve flow of the foam into all crevices, delayed-action catalysts are employed. These are carboxyl $t$-amine salts. The formic acid salts of 1-(2-hydroxypropyl)imidazole, N,N,N',N'-tetramethyl1,2-ethanediamine, and the 2-ethylhexanoic acid salt of 1,8-dia-zabicyclo [5.4.0]undec-7-ene (DBU) are examples of delayed-action catalysts [6]. Gelation catalysts catalyze the reaction of the isocyanate groups with hydroxyl groups of the polyol and in foams dibutyltin compounds, stannous octoate and triethylenediamine, (1,4-diaza-bicyclo [2.2.2] octane) are employed.

Many of the newer coating systems use polyisocyanates or blocked isocyanates as crosslinkers for hydroxyl functional polymers. Isocyanate chemistry permits the formation of extremely resistant coatings at low cure temperatures. Polyurethanes can be used in many coating application processes like waterborne, high solids and powder coatings. The most common catalysts for the reaction of aliphatic isocyanate or blocked isocyanates with hydroxyl groups are organotin compounds. The standard catalyst is dibutyltin dilaurate (DBTDL). DBTDL is a very effective, but not a selective catalyst. Besides catalyzing the isocyanate-hydroxyl reaction, DBTDL also catalyzes the water reaction and the hydrolysis of ester groups. Although dibutyltin compounds are of lower environmental toxicity than tributyltin compounds, dibutyltin is the hydrolysis prod- uct of tributyltin antifouling compounds, which are of high environmental concern. We have shown in our work that non-tin compounds can be used as catalysts in polyurethane formation. These catalysts are not only environmentally more acceptable, they also offer a different performance profile. For example, aluminum chelates [7] in the presence of small amounts of 2,4-pentanedione are excellent catalysts for high solids, polyol-isocyanate coatings giving exceptional potlife [8] and fast reaction. After cure, aluminum chelates will hydrolyze on exposure to moisture, thus be deactivated and not pose any environmental problems. Other catalysts, which are effective in two component isocyanate coatings, are zirconium complexes.

Zirconium complexes [9] give extremely high reaction rates in isocyanatepolyol systems and are more efficient than dialkyltin compounds. Fig. 2 and 3 illustrate the effect of different levels of DBTDL catalyst and zirconium chelate catalyst on the gel time and dry through time of a high solids acrylic/aliphatic isocyanate coating formulation. Addition of 2,4-pentanedione can substantially improve the stability of a zirconium and aluminum chelate (Fig. 4) catalyzed formulation without any impact on the dry through time of the formulation.

Residual catalyst can have an effect on the hydrolytic stability of an estercontaining coating. The hydrolytic stability of a polyester in THF and water was studied at $50{ }^{\circ} \mathrm{C}$ for 18 weeks (Fig. 5). The uncatalyzed formulation (control) shows an increase in acid number from $<1$ to 4 due to hydrolysis. A formulation containing a dibutyltin diacetate (DBTDac) catalyst increases substantially in acid number, whereas the $\mathrm{Zr}$ and $\mathrm{Al}$ chelate catalyzed formulations and the bismuth carboxylate catalyzed formulations show no increase in acid number.

Zirconium catalysts are also selective [10] in catalyzing the isocyanate-hydroxyl reaction over the water reaction and have found applications as catalysts for selected waterborne two component 

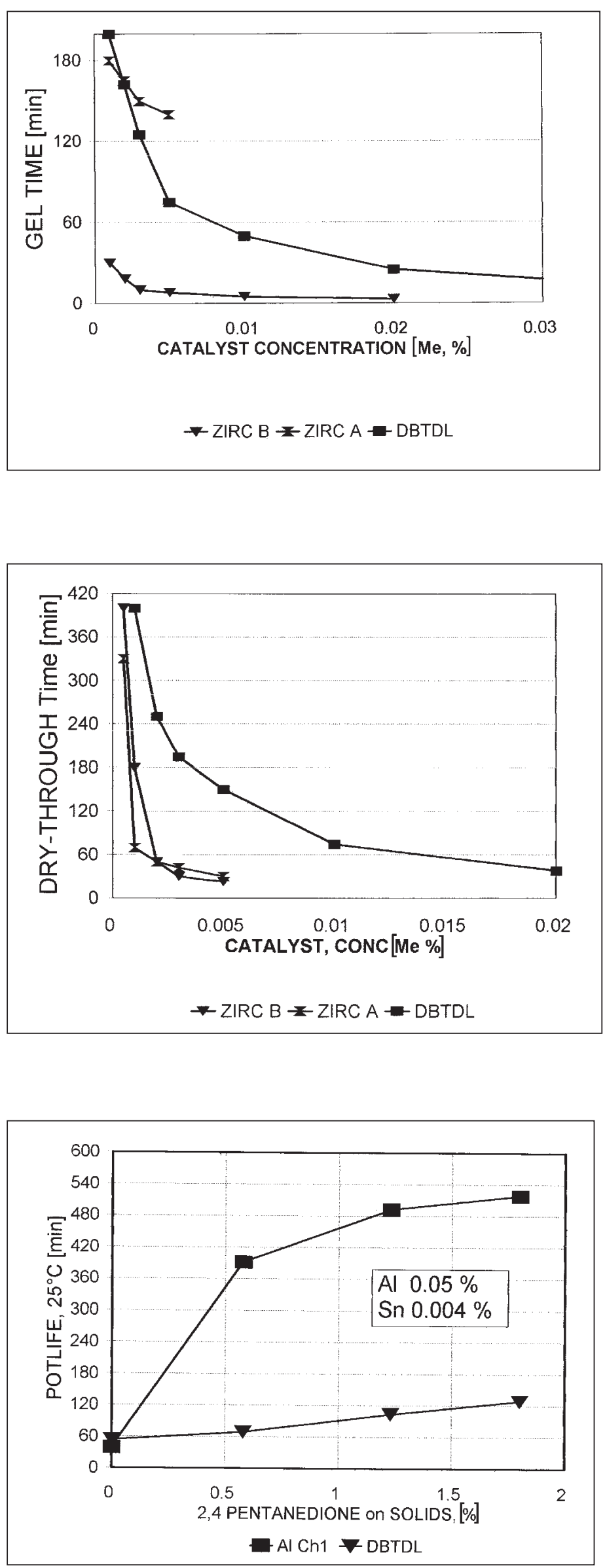

Fig. 4. Improvement in potlife for a high solids polyester-1,6-hexanediisocyanate isocyanurate cross-linked formulation on addition of 2,4-pentanedione. Catalysts DBTDL and Al chelate. Catalyst levels based on resin solids.
Fig. 2. Gel time of a high solids acrylic polyol crosslinked with 1,6hexanediisocyanate isocyanurate and catalyzed with DBTDL and zirconium chelate catalyst. ZIRC B commercially available catalyst, ZIRC A formulation stabilized with excess of 2,4-pentanedione.

Fig. 3. Dry through time of high solids acrylic polyol crosslinked with 1,6-hexanediisocyanate isocyanurate catalyzed with DBTDL and zirconium chelate catalyst. ZIRC B commercially available catalyst, ZIRC A formulation stabilized with excess of 2,4-pentanedione.

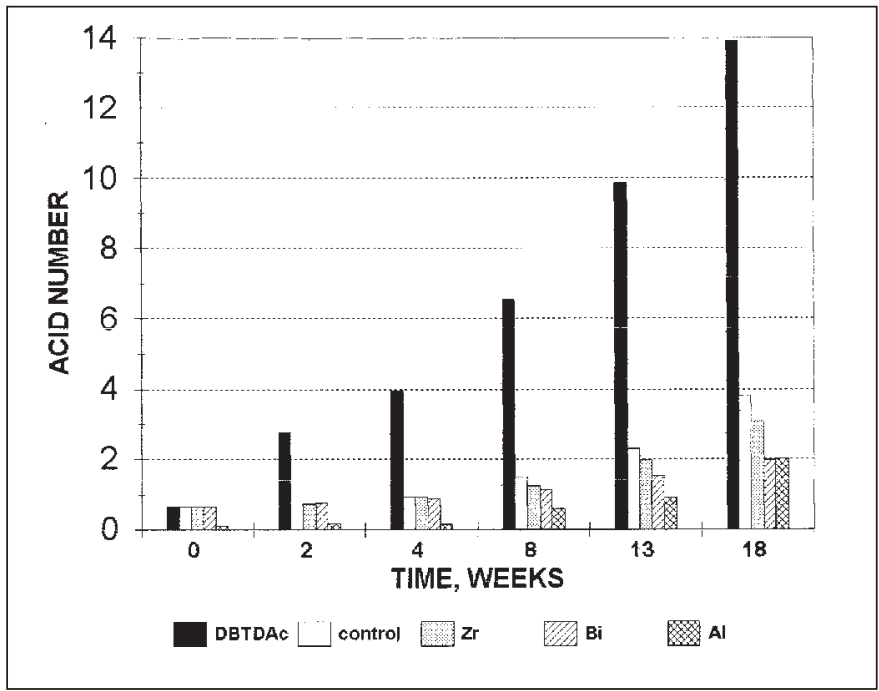

Fig. 5. Effect of catalyst on the hydrolytic stability of a polyester in the presence of water at $50{ }^{\circ} \mathrm{C}$. Catalysts used DBTDac, Zr chelate, Al chelate and Bi carboxylate, $0.1 \%$ metal based on resin solids. Ratio of water to ester groups $2: 1$. 
coatings. Generally, it is understood that DBTDL functions as a Lewis acid catalyst and activates the isocyanate. We have found that the zirconium chelates operate by a different mechanism and activate the hydroxyl groups through the formation of an alkoxide. The intermediate has been confirmed by ${ }^{13} \mathrm{C}$ NMR (Formula 1).

Blocked isocyanate crosslinked coatings are used in applications where stable, one-component coating formulations are required, higher cure temperatures are acceptable and also where the performance properties of an isocyanatecrosslinked coating is needed. DBTDL is an effective catalyst for ketoxime, dimethylpyrazole, phenol and alcohol blocked isocyanates. In applications such as cationic electrocoating, lead compounds were used as corrosion inhibitors and as catalysts for alcohol-blocked isocyanates. Many of the lead-containing electrocoating formulations have been reformulated to use dibutyltin oxide and more recently to bismuth compounds as catalysts. In Europe this conversion to non-tin catalysts for electrocoating is ahead of the change in the USA. Bismuth compounds [11] have the advantage of very low toxicity and also offer corrosion protection, which is not the case for dibutyltin oxide. Often, dibutyltin is used as a dispersion of dibutyltin oxide in the electrocoating tank.

The catalysis [12] of uretdione internally blocked isocyanate is of interest in powder coatings. Uretdione has the advantage over other blocked isocyanates of not emitting any volatile reaction products. The most effective catalysts found thus far for uretdione deblocking are based on amidines.

\section{Amino Formaldehyde Resins}

Alkylated melamine-formaldehyde and urea-formaldehyde resins are one of the crosslinking chemistries practiced in industrial coatings, adhesives, laminating, textiles, and moldings. Because of the excellent combination of performance characteristics and low cost, they represent a large segment of the crosslinking market for industrial coatings. Concern about formaldehyde emission during application and from finished goods has decreased the use of amino crosslinker in wood coatings and adhesives. In automotive clearcoats the poor acid rain resistance of melamine crosslinked systems has led to their partial or complete replacement in some formula-

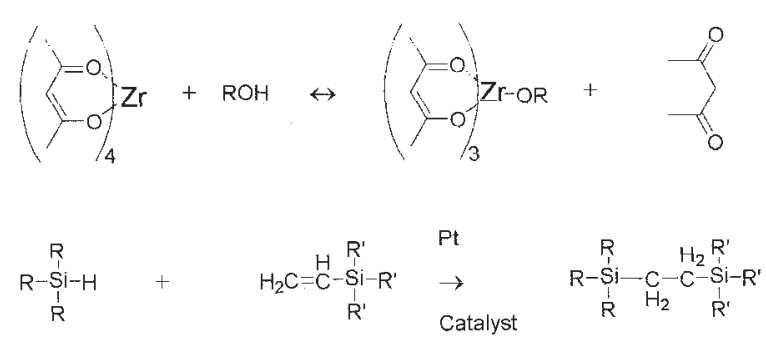

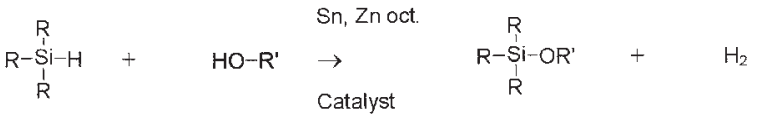

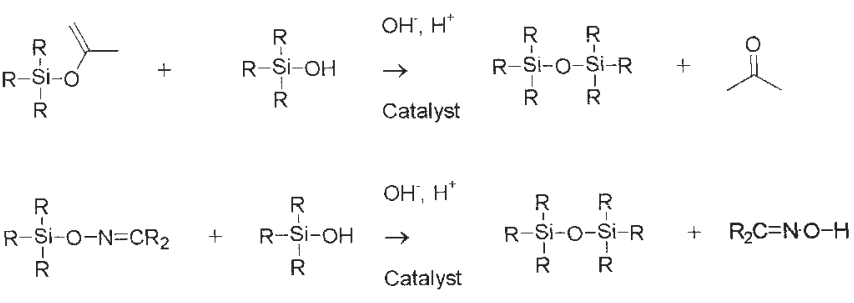

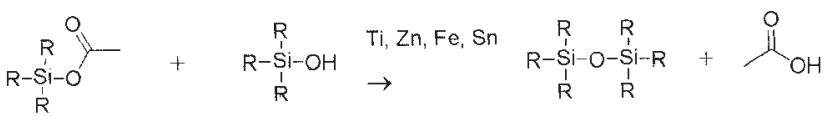

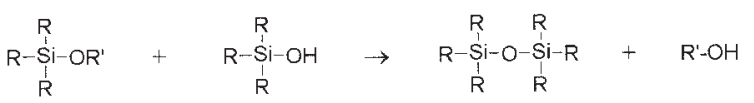

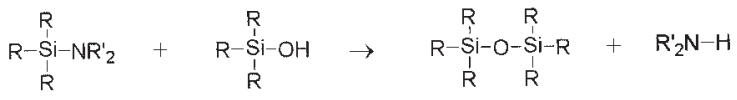

tions. Amino formaldehyde resins require acid catalysis for cure. Unalkylated and partially alkylated or imino type [13] melamine-formaldehyde resins respond to general acid catalysis. Weak acid catalysts, such as carboxyls or their salts, can be used to catalyze self-condensation or the reaction with hydroxyl functional polymers. Fully methylated melamine formaldehyde resins, also designated hexakis (methoxymethyl)-melamine (HMMM), were introduced by American Cyanamid in 1960. HMMM and its mixed ether derivatives are a substantial departure in reactivity and catalyst requirements from the conventional partially butylated melamine resin. HMMM is a very efficient crosslinker for hydroxyl, amide, carboxyl, carbamate, urethane and many activated $\mathrm{CH}$ [14] functional polymers. HMMM type crosslinker responds to specific acid catalysis and requires a strong acid catalyst for optimum reaction. The initial catalyst used was $p$-toluenesulfonic acid (pTSA). It has many disadvantages, including poor solubility in organic solvents and water resistance problems. The development of more hydrophobic dodecylbenzene sul- fonic (DDBSA), dinonylnaphthalene sulfonic acid [15] (DNNSA) and dinonylnaphthalene disulfonic acid [16] (DNNDSA) catalysts lead to coatings with improved water, humidity and corrosion resistance. Stability issues of sulfonic acid catalyzed formulations were overcome by blocking the acid catalyst with different amines or by preparing covalently [17] blocked sulfonic acids. Blocked DDBSA catalysts are the choice for automotive clearcoat applications. Good solubility in most solvents, light color and excellent exterior durability are the prime reasons for this choice. For applications which require good adhesion to metal substrates and improved chemical resistance and corrosion resistance, the more hydrophobic DNNDSA and DNNSA are used. pTSA is still used in areas where fast reaction at low temperature is required, such as wood and paper coating.

\section{Epoxy Resins}

The largest use for epoxy resins is in combination with amine curing agents in 
two component adhesives, composites and primer/maintenance coatings. The market for catalysts to accelerate the reaction of epoxy groups with other functional sites, such as anhydride or carboxyl groups or to catalyze the epoxy homo-polymerization, is much smaller. Most of the catalysts used to catalyze the epoxy-carboxyl or anhydride reaction are based on amine type catalysts. Metal chelate catalysts based on zinc compounds [18] have shown an advantage in yellowing and improved corrosion resistance (see Table 2 and Fig. 6).

The epoxy/carboxyl reaction is widely used in powder coatings. Catalysts are used in epoxy powder coatings: (1) to catalyze the reaction of glycidyl ester functional, acrylic resins with dicarboxylic acids or with carboxyl functional resins, (2) for crosslinking of carboxyl functional polyester resins with triglycidylisocyanurate (TGIC), and also (3) for hybrid powder coatings of bisphenol A diglycidyl resins with carboxyl-functional polyesters.

Other catalysts for epoxy resins fall in the category of cationic superacid catalysts. Superacids can catalyze the homogiving improved stability, reduction in

polymerization and co-polymerization of epoxies with hydroxyl functional polymers, cyclic ester, oxetane [20], and vinylether reactants. Most of the cationic catalysts are activated by UV radiation [21]. Recently, quaternary ammonium blocked hexafluoroantimonate and triflic acid catalysts [22] have been introduced for thermal cationic cure. These catalysts function by a rearrangement of the quaternary compound to a weak, basic amine.

\section{Siloxanes}

Silane-based chemistry is used in sealants, coatings, in backbone polymers, adhesion promoters and as a crosslinking mechanism. A large market for siloxanes is in sealant applications. Silicone chemistry is very versatile, permitting a wide range of chemical reactions, which can be used to achieve room temperature-stable one-pack, moisture-cure formulations or room temperature reacting, two component systems or also heat-cured systems. Vinyl-unsaturated terminated siloxanes are used in free radical coupling reactions and in addition reactions of methyl hydrogen functional siloxanes

Table 2. Potlife of a bisphenol A diglycidyl resin crosslinked with methyl tetrahydrophthalic anhydride and catalyzed with a zinc chelate and a 2-ethylimidazole catalyst.

$\begin{array}{llll} & \text { ZnCH [19] } & \text { 2-Ethylimidazole } & \text { Uncatalyzed } \\ \text { Original viscosity, cps, } 25^{\circ} \mathrm{C} & 900 & 900 & 900 \\ \text { Viscosity after } 24 \text { hours, } \mathrm{cps}, 25^{\circ} \mathrm{C} & 900 & 4,200 & 900 \\ \text { Pot life, } 25^{\circ} \mathrm{C} \text {, days } & >2 \text { weeks } & 3 \text { days } & >2 \text { weeks } \\ \begin{array}{l}\text { Cure cycle: } 1 \mathrm{~h} \text { at } 80^{\circ} \mathrm{C} \text { then } 3 \mathrm{~h} \\ \text { at } 150^{\circ} \mathrm{C}\end{array} & & & \\ \text { Hardness, Shore D } & 95 & 95 & \text { Liquid }\end{array}$
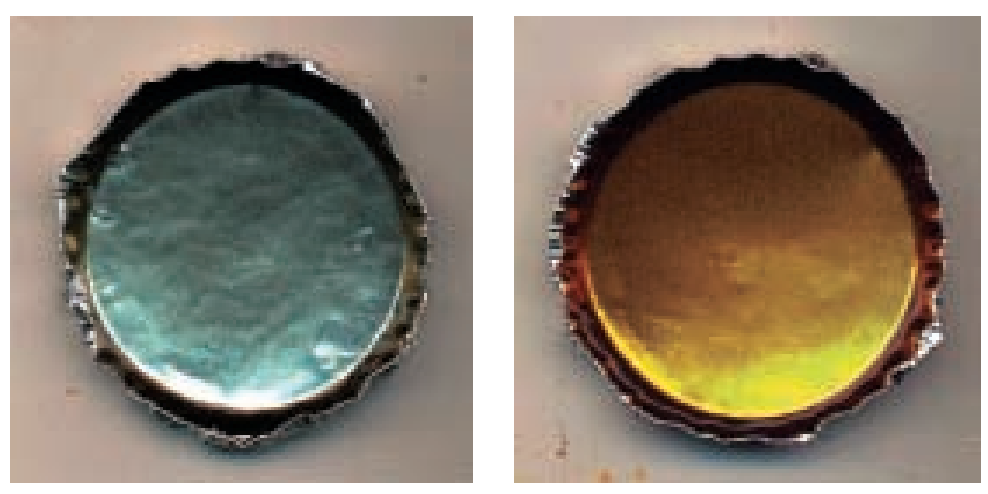

Fig. 6. Yellowing of a bisphenol A diglycidyl resin crosslinked with methyl tetrahydrophthalic anhydride and catalyzed with a zinc chelate and 2-ethylimidazole catalyst. (hydrides). This free radical coupling reaction is catalyzed by free radical initiators (Formula 2).

Vinyl terminated siloxanes require a platinum chelate [23] (Karstedt's catalyst) for the reaction with hydrogen terminated siloxanes. The reaction of polymethylhydrosilanes with olefins in the presence of precious metal catalysts is widely used in (room temperature vulcanized) RTV and (low temperature vulcanized) LTV elastomers (Formula 2).

Polymethylhydrosilanes are also of interest in the reaction with hydroxyl groups leading to alkoxysilanes. This reaction is catalyzed by zinc and tin octoate catalysts (Formula 3). Moisture activation is used in many silanol-terminated polydimethyl-siloxanes with acryloxy, enoxy, oxime, alkyloxy or amine terminated reactants siloxanes. Again, RTV elastomer is a major market for these systems. The self-condensation reaction of alkoxysilanes with sulfonic acids is used in curing of automotive clearcoats [24] and in polyethylene wire coatings [25]. The reaction of alkoxysilanes can also be catalyzed with aluminum and zirconium dionate complexes. (Formulae 4, 5, 6, 7, 8)

The catalysts used in the silanol reactions are the organotin compounds and the titanium [26], zinc, zirconium [27], iron [28], and stannous [29] carboxylates and chelates. For the reaction of alkoxyterminated siloxanes in moisture cure applications, organotin compounds and also sulfonic acid catalysts can be used.

\section{Unsaturated Polyester Resins}

Unsaturated maleic or fumaric polyesters represent a major business of glass fiber reinforced applications in boats, sanitary installations, such as shower stalls and bath tubs. The use of this technology in high volume OEM applications, such as automotive, is limited to some manufacturers and some car models. Small amounts of these polymers are used in corrosion resistant chemical containers. In coatings, this chemistry is used predominately on wood. Besides maleic polyesters, vinyl-group terminated polymers are also used in special applications. Unsaturated polymers are often used in combinations with low molecular weight monomers, such as styrene, acrylic ester or allylic compounds. These compounds are cured by a free radical mechanism. The use of catalysts, which generate free radicals by UV, is possible. For heat or ambient cure, the generation of free radi- 
cals is also possible with free radical initiators. The free radicals can be directly generated by thermal decomposition of a peroxide or azo initiator or from peroxides in the presence of cobalt or amine activators. Cobalt octoate is used in polyester resins initiated by methylethylketone peroxide and tertiary amines [30] such as N,N-dimethyl-aniline, N,N-dimethyl- $p$-toluidine, N,N-dihydroxyethyl$p$-toluidine, $p$-tolyl-diethanolamine and N,N,N',N'-tetramethylethylenediamine.

The Michael addition of unsaturated compounds to amines or acetoacetates is one of the reactions which has been promoted as an alternative [31] for isocyanate crosslinking at room temperature. The addition reaction of amines to acrylates does not require catalysis. Reaction of acetoacetates with acrylates is a base-catalyzed reaction. A strong base [32] is required to achieve low temperature cure. Typical organic catalysts useful for this reaction are tetramethylguanidine, DBU (1,8-diazabicyclo[5.4.0] undec-7-ene), DBN (1,5-diazobicyclo [4.3.0]non-5-ene), and quaternary ammonium compounds [33]. The Michael addition reaction in the presence of basic catalysts is very fast and the potlife is short. The cure reaction can be inhibited by carbon dioxide and acidic compounds. Blocking of the amine catalyst with formic acid [34] extends the potlife at room temperature from minutes to month. Cure at room temperature is inhibited and a cure temperature of $>80{ }^{\circ} \mathrm{C}$ is required. Retardation of cure can also be achieved with alcohols [35].

The selection of an appropriate catalyst is essential for the formulation of a coating system. Not only are catalysts required to accelerate the reaction of the reactants, catalysts have a substantial effect on the application characteristics, performance properties and long term durability.

Received: March 28, 2002

[1] J.J. Florio, King Ind., 'Troubleshooting Metal Catalyzed Urethane Systems', PCI Magazine Sept, Norwalk, CT, USA, 2000.

[2] Z.N. Medved, N.A. Starikova, A.K. Zhitinkina, O.G. Tarakanov, N.A. Tolstykh, Vses. Nauchno-Issled. Inst. Sint. Smol, Vladimir, USSR, 'Cyclotrimerization of isocyanates in the presence of potassium acetate-based catalytic systems', Sint. Fiz.-Khim. Polim. 1976, 18, 39-43.

[3] K.C. Tang, P.T. Berkowitz, Olin Corp., 'Trimerizing organic polyisocyanates', US Pat. 4,503,226, 1985.

[4] H. Yoshimura, Y. Tamano, S. Okuzono, D.W. Lowe, Tosoh Corp. Shin-Nanyo,
746, Japan, 'An insight into the characteristics of a nucleation catalyst in CFC-free rigid foam systems', J. Cell. Plast. 1996. 32(4), 367-389.

[5] A. Ishikawa, M. Sakai, M. Morii, Kao Corp., 'Odorless process for producing polyurethanes useful for insulation application with good dimensional stability and freedom from fogging and vinyl staining', PCT Int. Appl., WO 2001044337, 2001.

[6] S.T. Terry, Pittsburgh Plate Glass Co, 'Preparation of polyurethane foam utilizing a salt of dimethylethanolamine and a dicarboxylic acid as a catalyst', US Pat. 2,932,621, 1960.

[7] Aluminum Chelate K-KAT 5218 a product of King Industries Inc, Norwalk, CT 06852, USA.

[8] W.J. Blank, 'Catalysis of the isocyanatehydroxyl reaction by non-tin catalysts', Prog. Org. Coat. 1999, 35(1-4), 19-29 (English), Elsevier Science.

[9] K-KAT XC-6212, XC-9213 products of King Industries Inc, Norwalk, CT 06852 , USA.

[10] Z.A. He, W.J. Blank, M.E. Picci, 'A selective catalyst for two component waterborne polyurethane coatings', Proc. Int Waterborne, High-Solids, Powder Coat. Symp., 26th, 157-170 (English), 1999, University of Southern Mississippi, Dept. of Polymer Science.

[11] R. Feola, B. Burgmann, F. Kurzmann, (Vianova Kunstharz A.-G., Austria), 'Bismuth salts as curing catalysts in cathodic electrophoretic coating', PCT Int. Appl. WO 9507377, 1995.

[12] U. Freudenberg, H.U. Meier-Westerhues, H.J. Laas, 'Polyuretdione hardeners for non-blocked PUR powder coatings', (Business Group Coating Raw Materials, Bayer A.-G., Leverkusen, Germany), Eur. Coat. J. 1997(9), 804-808, Vincentz.

[13] W.J. Blank, 'Reaction Mechanism of Amino Resins', J. Coat. Techn. 1979, 51, No. 656, 61-70.

[14] W.J. Blank, 'Melamine Formaldehyde Networks with Improved Chemical Resistance', ACS PMSE Preprints Las Vegas Meeting, 1997.

[15] NACURE ${ }^{\circledR} 1051$, a product of King Industries Inc, Norwalk, CT 06852.

[16] NACURE $^{\circledR} 155$ a product of King Industries Inc, Norwalk, CT 06852

[17] W.J. Blank, King Industries Inc., US Pat. 5,102,961: 'Isocyanate modified blocked sulfonic acid ester as a crosslinking catalyst'.

[18] W.J. Blank, King Industries Inc., 'Catalysis of the epoxy-carboxyl reaction', Proc. Int. Waterborne, High-Solids and Powder Coatings Symposium Feb. 21-23, 2001 , New Orleans, LA, USA.

[19] NACURE XC 9206 a product of King Industries, Inc. Norwalk, CT 06852.

[20] J.V. Crivello, H. Sasaki; 'Oxetanes, their ultraviolet-hardenable compositions, and their crosslinked polymers' (Rensselaer Polytechnic Institute, USA), Jpn. Kokai Tokkyo Koho JP 07017958, 1995.

[21] J.V. Crivello, S.A. Bratslavsky, 'A. Study of the cationic photopolymerization of multifunctional propenyl ether mono- mers' (Dep. Chem., Rensselaer Polytechnic Institute, Troy, NY 12180, USA), $J$. Macromol. Sci., Pure Appl. Chem. 1994, A31(12), 1927-41.

[22] R.P. Subrayan, D.J. Miller, M.M. Emmet, W.J. Blank, 'Catalysis of Thermally Curable High Solids Cycloaliphatic Epoxy Formulations', ACS PMSE Preprints Chicago Meeting, 2001.

[23] H. Enami, Dow Corning Toray Silicone Co., Ltd., JP 2000080345, 2000.

[24] I.C. Hazan, J.D. Nordstrom, 'Coating composition of an acrylic polymer, a crosslinking agent and a silane oligomer', E.I. Du Pont de Nemours, US 5,066,698, 1991.

[25] R. Dammert, B. Gustafsson, B.-Å. Sultan, 'Polyethylene compatible sulfonic acids as silane crosslinking catalysts', WO 9517463A, Borealis Holding, 1995.

[26] P. DeLaTorre, M. D. Beers, US Pat. $4,102,852$, 'Self-extinguishing room temperature vulcanizable silicone rubber compositions', General Electric Company, 1978.

[27] W.R. Lampe, 'Low modulus room temperature vulcanizable silicone rubber compositions', US Pat. 4,410,677, General Electric Company, 1983.

[28] S.J. Bessmer, W.R. Lampe, 'Self-bonding two-package room temperature vulcanizable silicone rubber compositions', General Electric Company, US Pat. 3,888,815, 1975.

[29] R.A. Smith, 'Catalyst composition for room temperature vulcanizing silicone compositions and catalyzed compositions', General Electric Company, US Pat. 3931047, 1976.

[30] F. Storey, D. Sudhakar, M. Hogue, J. Appl. Polym. Sci. 1986, 32, 4919.

[31] A. Noomen, 'Applications of Michael addition chemistry in coatings technology', Akzo Nobel Coatings B.V., Prog. Org. Coat. 1997, 32(1-4), 137-142, Elsevier Science

[32] R.J. Clemens, 'Low-temperature Michael addition in crosslinking', Eastman Kodak Co., US Pat. 5,017,649, 1988.

[33] T. Imamura, K. Ishii, 'Michael addition reaction curable coating composition', Nippon Paint Co., Ltd. JP 10330690, 1998

[34] T. Li, J.C. Graham, 'Use of formic acid in controlling the rate of the Michael addition reaction in base-catalyzed, thermally cured acetoacetylated acrylic/trimethylolpropane triacrylate coatings' (East. Michigan Univ., MI, USA), J. Coat. Technol. 1993, 65(821), 63-69.

[35] J.C. Graham, T. Li, W. Tao, 'The role of alcohols in modifying the rate of base catalyzed Michael addition reaction at room temperature', Res. Inst., East. Michigan Univ., Ypsilanti, MI 48197, USA, Proc. Water-Borne, Higher-Solids, Powder Coat. Symp., 20th, 273-83, 1993. 